\title{
Associations between parents' subjective time pressure and mental health problems among children in the Nordic countries: a population based study
}

Hrafnhildur Gunnarsdottir ${ }^{1,2^{*}}$, Ylva Bjereld ${ }^{3}$, Gunnel Hensing ${ }^{1}$, Max Petzold ${ }^{4}$ and Lene Povlsen ${ }^{5}$

\begin{abstract}
Background: The home, the family and the parents represent a context of everyday life that is important for child health and development, with parent-child relationships highlighted as crucial for children's mental health. Time pressure is an emerging feature of modern societies and previous studies indicates that parents with children living at home experience time pressure to a greater extent than people with no children living at home. Previous studies of children's mental health in relation to parents' time pressure are lacking. Hence, the purpose of this study was to examine the association between parents' subjective time pressure and mental health problems among children in the Nordic countries as well as potential disparities between boys and girls in different age groups.

Methods: 4592 children, aged 4-16 from Denmark, Finland, Norway and Sweden, participating in the 2011 version of the NordChild study, were included. The Strength and Difficulties Questionnaire was used to measure children's mental health and associations to parents' time pressure were assessed by multiple logistic regression analysis.

Results: Among children of parents experiencing time pressure, $18.6 \%$ had mental health problems compared to $10.1 \%$ among children of parents experiencing time pressure not or sometimes. The odds of mental health problems were higher among both boys (OR 1.80 95\% Cl 1.32-2.46) and girls (OR $1.9595 \% \mathrm{Cl} 1.42-2.66)$ if their parents experienced time pressure when adjusted for financial stress. The highest prevalence of mental health problems in the case of parental time pressure was found among girls 13-16 years old (23.6\%) and the lowest prevalence was found among boys 13-16 years old (10.7\%).

Conclusions: In this study an association between parents' subjective time pressure and increased mental health problems among children was found. Given that time pressure is a growing feature of modern societies, the results might contribute to an explanation as to mental health problems are common among children in the Nordic countries in spite of otherwise favourable conditions. Additional research on the linkage between parents' experienced time pressure and children's and adolescents' mental health problems is needed to confirm the novel findings of this study.
\end{abstract}

Keywords: Time pressure, Parents, Child mental health, Strength and difficulties questionnaire, Nordic countries

\footnotetext{
* Correspondence: hildur.gunnarsdottir@hv.se

${ }^{1}$ Department of Public Health and Community Medicine, Section of Social

Medicine, Sahlgrenska Academy at University of Gothenburg, Gothenburg,

Sweden

${ }^{2}$ Department of Nursing, Health and Culture, University West, 46186

Trollhättan, Sweden

Full list of author information is available at the end of the article
}

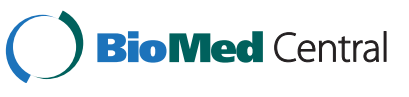

(C) 2015 Gunnarsdottir et al.; licensee BioMed Central. This is an Open Access article distributed under the terms of the Creative Commons Attribution License (http://creativecommons.org/licenses/by/4.0), which permits unrestricted use, distribution, and reproduction in any medium, provided the original work is properly credited. The Creative Commons Public Domain Dedication waiver (http://creativecommons.org/publicdomain/zero/1.0/) applies to the data made available in this article, unless otherwise stated. 


\section{Background}

The context of the present study is the welfare state of the Nordic countries where family policies supporting dual-earner/dual-carer families are prominent. The essence of the dual-earner/dual-carer model consists of favourable parental leaves and generous day care services, which enable parents to share paid work and care of children [1,2]. Implicit in the dual-earner/dual-carer model is a need to balance roles and responsibilities in the work and family domains, which can be complicated and cause conflicts [3]. Women's participation in the labour market is high in the Nordic countries and women still assume the main responsibilities for housework even though the disparities between men and women's total amount of time spent in work (paid and housework) have declined throughout the last decades. Men are taking a larger share of housework responsibilities than ever before, while mothers in all of the Nordic countries are still devoting more time to childcare than fathers [4-7]. Time pressure evolves if there is a discrepancy between the standards and/or the ambitions of what people want to or have to do within the domains of everyday life and the realisations of these. If time pressure is perceived as out of control or chronic it gets problematic and threatening to health [8]. Time pressure is a complex feature of modern societies [8] that has emerged as a considerable social problem [9] and has become a common theme in popular discourse [10]. It concerns the organisation of social practices within a certain time unit $[8,10]$ and its emergence has been related to economic, cultural and technological changes of society $[9,10]$. Related to economic changes, time efficiency in production has become crucial for economical profit; leading to consistent competition to achieve the largest possible output per time unit [9]. This often results in employees working long hours, working faster and being accessible and flexible [10]. Technological changes characterising modern societies have made multi-tasking a natural pattern that has led to intensified social practices [8]. Cultural changes towards the idea of "the good life" consisting of doing as much as possible during a lifetime have resulted in individuals attempting to do everything as fast as possible [9].

Two dimensions of time pressure have been highlighted as important to recognize, one objective and one subjective [11]. The objective dimension embraces the crude lack of time, a quantifiable event and possibly controllable, that can be captured by time diaries where people measure their time allocation in different fields of everyday life. The subjective dimension embraces the experience of time pressure as feelings of fragmented time, demands to do things faster and constantly being rushed [11]. Previous research indicates that parents with children living at home experience time pressure to a greater extent than others $[12,13]$. Previous studies have as well indicated that parents of young children perceive time pressure to be challenging to health lifestyles of their children and family $[14,15]$ and that time pressure can have negative effects on parental mental health [16,17]. Parents' experiences of time pressure have previously been found to be associated with lack of support, financial stress, long working hours and parenting younger children [18].

The home, family and parents, represent a context of everyday life that is crucial for child health and development [19]. Bronfenbrenner [20,21] conceptualises this in his ecological model of human development, which embraces the structural systems affecting the individual and the family. The family as a unit and its intra-familial processes represent the microsystem in Bronfenbrenner's model, which is to a great extent influenced by processes in the mesosystem, the other settings in which the family members are participating (e.g. schools for children), as well as the exosystem level, which are the settings in which members are not directly participating (e.g. parents work for children) [21]. The macrosystem level then represents the cultural and political environment embracing the other systems and between all the systems a reciprocal interaction exists [20]. Drawing upon Bronfenbrenner's model, the emerging time pressure in modern societies can be considered not only of importance for parental mental health but children's as well.

Children's mental health problems embrace a broad range of behavioural, emotional and mental disorders and are currently considered a main public health concern. Estimating the global prevalence of mental health problems is challenging due to differences in methods and measurement, however, referencing studies of representative samples of children with psychiatric diagnoses, Kieling et al. [22] concluded that mental health problems affect $10-20 \%$ of children and adolescents worldwide. Moreover, mental health problems among children and adolescents in the Nordic countries are considered common [23], in spite of the family friendly policies. The aetiology of children and adolescents' mental health problems is complex, embraces a range of individual, familial and societal factors [22] and needs to be considered from various perspectives, one of which is the parents'. Grant et al. [24] propose a general conceptual model of the role of stressors in the aetiology of child psychopathology (Figure 1). The model illustrates how stressors (embracing a broad range of stressful experiences, from daily hassles to traumatic life events) contribute to child and adolescent psychopathology through moderating factors and mediating processes [24].

To our knowledge no previous studies have investigated the relationship between parents' time pressure and children's mental health problems. However, previous studies have found associations between other parentrelated stressors, such as high parental stress [25] and work-family conflicts [26] and mental health problems 


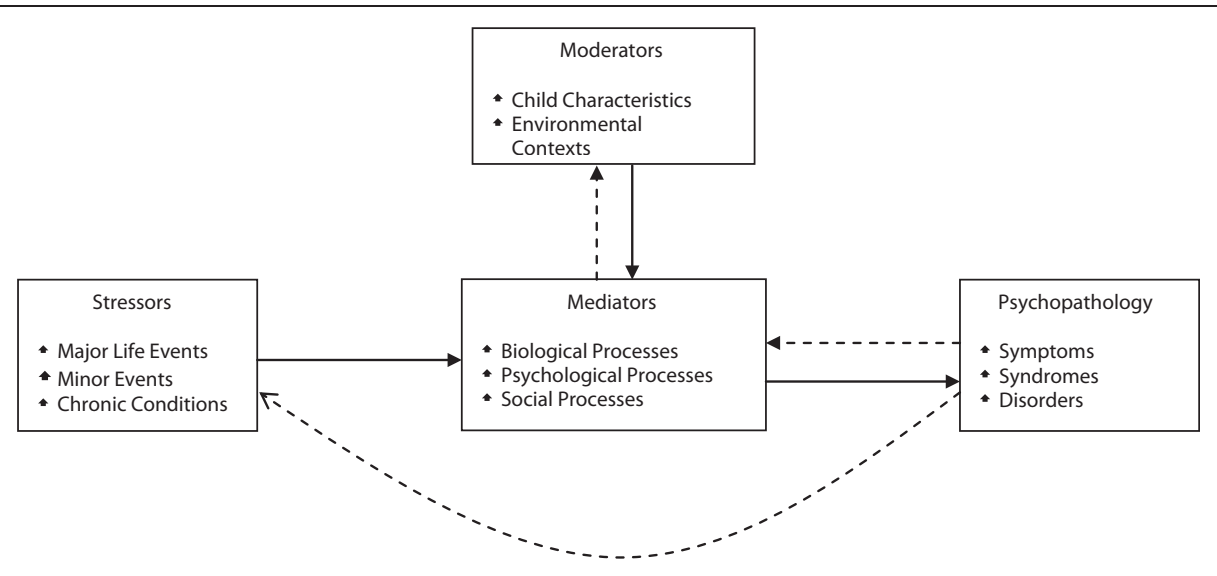

Figure 1 General conceptual model of the role of stressors in the aetiology of child and adolescent psychopathology from Grant et al. [24].

among children. Previous studies have also indicated that girls react more negatively to stressors than boys [27-29] and that the gender differences in stress reactions generally appear during adolescence [30,31].

Drawing on the view of time pressure as an emerging social problem contributing to tensions in children's ecological systems of development and a gap in the research area, the aim of our study was to examine the association between parents' perceived time pressure and children's mental health problems. The focus was on the subjective dimension of time pressure and attempts were made to capture an aggregated picture of the conditions of families with children in the Nordic welfare states by using data from four Nordic countries (Denmark, Finland, Norway and Sweden). The broad age span (4-16 years) of participants also enabled analysis of gender differences in different age groups.

\section{Methods}

\section{Participants}

The present study was part of the 2011 version of the Nordic Study of Children's Health and Wellbeing (NordChild) which is a cross-sectional survey conducted in the five Nordic countries Denmark (DK), Finland (FI), Iceland (IS), Norway (NO) and Sweden (SE). Ethical approval was achieved according to the prescribed guidelines in each of the Nordic countries. In DK the National Committee on Health Research Ethics, in FI the National Committee on Medical Research Ethics (TUKIJA), in IS the National Bioethics Committee, in NO Regional Committee for Medical and Health Research Ethics, REC South Easth and in SE the Regional Board of Ethical Vetting in Gothenburg.

Stratified sampling based on age and gender was made from the total population of children aged $2-17$ years old and consisted of approximately 3000 children from each country, randomly sampled from the strata. A postal questionnaire addressed to the child's primary care giver was used and the overall response rate after reminders was $48.8 \%$.

The present study's population consisted of parents of children 4-16 years old from DK, FI, NO and SE ( $\mathrm{n}=$ 4952) who answered a question about their experience of time pressure in everyday life. Of the parents who answered the questionnaire (considered themselves the child's primary caregiver) $83.0 \%$ were mothers, $14.6 \%$ fathers and $2.4 \%$ others/not.

\section{Measurements \\ Mental health problems}

The American Academy of Paediatrics (AAP) [32] defines mental health problems as behavioural or emotional signs or symptoms that cause impairment but do not necessarily meet the diagnostic criteria for a mental health disease/ psychiatric diagnosis. They further describe that the term encompasses neurodevelopmental, psychological, socioemotional problems as well as substance abuse and adjustment to stressors. Moreover, mental health problems can also embrace psychosomatic symptoms as fatigue, headaches, eating disorders and functional gastrointestinal symptoms [33]. The aspects of children's mental health problems measured in this study were hyperactivity, emotional, peer and behavioural problems captured by the parental version of Strengths and Difficulties - Total Difficulties Score (SDQ-TDS), which previously has been found a comprehensive measurement of overall mental health problems among children 4-16 years old [34-37]. The Strengths and Difficulties Questionnaire (SDQ) is a widely used instrument $[38,39]$, which has been translated and found valid for use in all the Nordic countries [40] and was included in the 2011 version of the NordChild survey. The SDQ consists of 25 items covering emotional, peer and behavioural problems as well as hyperactivity and pro-social behaviour divided into five subscales [38]. Each subscale generates a score ranging from zero to 10 . The SDQ-TDS is the sum of the hyperactivity, emotional 
problems, conduct problems and peer problems scales, generating a scale score ranging from zero to 40 [38]. The SDQ-TDS has been found suitable for screening for mental health problems among children in normal populations and found to correspond sensitively with clinical diagnoses of psychiatric disorders [41]. As recommended [38,42] the $90^{\text {th }}$ percentiles were used as cut-offs for mental health problems. Previous studies have observed gender and age specific differences in the scoring on the SDQ $[35,42]$. Hence the cut-offs were calculated for each gender and the age groups: preschool children (4-6 years old), primary school children (7-12 years old) and adolescents (13-16 years old). Children scoring over the cut-off point of their gender and age group were categorised as having mental health problems.

\section{Parents' subjective time pressure}

The subjective dimension of time pressure was assessed by the question, "Do you feel rushed when keeping up with the duties of everyday life?" previously used in studies of time use and time pressure [13,43]. Response alternatives were: Yes most often, Yes sometimes or No. Drawing upon Garhammer's [8] definition of time pressure becoming problematic when experienced out of control or chronic, the exposure of interest was parents reporting feelings of rush 'most often'. Thus the answers were dichotomised to 'most often' and 'no/sometimes' in the analysis and parents answering 'most often' are hereafter referred to as experiencing time pressure or time-pressured.

\section{Potential confounding variables}

The choice of covariates of interest was made by theoretical selection among variables possibly influencing both parents' subjective time pressure and child mental health status. Bullying victimisation was considered important because of it being a strong predictor of the child's mental health $[44,45]$ and possibly increasing parents' experience of time pressure, measured by the question, "Is your child being bullied?" (Yes often/sometimes or No/don't know). Child family and living conditions are widely recognised determinants of child health [46] and previous studies have found them to be associated with parents' experienced time pressure $[9,18]$. Family and living conditions were assessed by family financial stress (inability to pay ordinary bills and/or lack of cash reserves), parents' educational level (university level or lower educational level), parents' civil status (married/cohabiting or single parent), and parents' working hours per week $(<37$ hours, 37-40 hours or $>40$ hours). Parents' health/wellbeing was considered a possible confounding factor and was assessed by reported sick leave (long term $=$ more than 60 days during the last twelve months). Furthermore, child long-term illness (LTI) was considered a possible confounder and defined as one or more modest or severe physical symptoms presented for at least three months throughout the last year.

\section{Statistical analysis}

SPSS version 20.0 was used for the statistical analysis. The mean TDS and the proportion of children with mental health problems (scoring above the $90^{\text {th }}$ percentile) were calculated among children of parents experiencing time pressure as well as children of parents who were not/sometimes experiencing time pressure.

A bivariate logistic regression analysis was performed to measure the association between parents' subjective time pressure and children's mental health problems in total as well as age and gender specific. Then a stepwise logistic regression model was built to adjust for covariates considered potential confounders. In the first step each covariate's effects on the parameter estimate were assessed. If resulting in changes in parameter estimates for parents' time pressure $>10 \%$ the covariate was included in the final model. The final regression model was used to calculate the adjusted odds ratios (OR) for the whole sample as well as for age and gender specifically. Additionally the final regression model was used to calculate the adjusted ORs for the whole sample of children in each country.

\section{Results}

Country specific characteristics of the participating children are shown in Table 1.

A statistically significant difference in the prevalence of mental health problems was observed among children of parents who experienced time pressure (18.6\%) compared with children of parents who did not or sometimes experience time pressure (10.1\%), see Table 2 . When stratified by age and gender the highest prevalence of mental health problems in the case of parental time pressure was found among girls 13-16 years old $(23.6 \%)$ and the lowest prevalence was found among boys 13-16 years old (10.7\%). The adolescent boys of time-pressured parents did not have higher prevalence of mental health problems when compared to adolescent boys of parents without time pressure.

The regression analysis showed that both boys and girls had higher odds of mental health problems if parents were experiencing time pressure compared with parents who did not or sometimes experience time pressure. When adjusted for financial stress (the only confounding variable affecting the parameter estimate $>10 \%$ ), boys had 1.80 (95\% CI 1.32-2.46) times higher and girls 1.95 (95\% CI 1.42-2.66) times higher odds of mental health problems if their parents experienced time pressure (Table 3). The odds of mental health problems were higher among children of both time pressured mothers (OR 2.07, 95\% CI 
Table 1 Country specific characteristics of participants

\begin{tabular}{|c|c|c|c|c|c|}
\hline & $\begin{array}{l}\text { Denmark } \\
(n=1314) \\
n(\%)\end{array}$ & $\begin{array}{l}\text { Finland } \\
(n=1181) \\
n(\%)\end{array}$ & $\begin{array}{l}\text { Norway } \\
(\mathrm{n}=1288) \\
\mathrm{n}(\%)\end{array}$ & $\begin{array}{l}\text { Sweden } \\
(\mathrm{n}=1169) \\
\mathrm{n}(\%)\end{array}$ & $\begin{array}{l}\text { Nordic countries } \\
(\mathrm{n}=4952) \\
\mathrm{n}(\%)\end{array}$ \\
\hline \multicolumn{6}{|l|}{ Gender: } \\
\hline Boy & $669(50.9)$ & $579(49.0)$ & $654(50.8)$ & $593(50.7)$ & $2495(50.4)$ \\
\hline Girl & $645(49.1)$ & $602(51.0)$ & $634(49.2)$ & $576(49.3)$ & $2457(49.6)$ \\
\hline \multicolumn{6}{|l|}{ Age: } \\
\hline 4-6 years & $335(25.5)$ & $297(25.1)$ & $290(22.5)$ & $276(23.6)$ & $1198(24.2)$ \\
\hline $7-12$ years & $607(46.2)$ & $585(49.5)$ & $612(47.5)$ & $544(46.5)$ & $2348(47.4)$ \\
\hline $13-16$ years & $372(28.3)$ & $299(25.3)$ & $386(30.0)$ & $349(29.9)$ & $1406(28.4)$ \\
\hline Mean SDQ-TDS (SD) ${ }^{\mathrm{a}}$ & $7.7(4.3)$ & $7.9(4.1)$ & $7.3(4.2)$ & $7.3(4.2)$ & $7.6(4.2)$ \\
\hline \multicolumn{6}{|c|}{ Parents experiencing time pressure: } \\
\hline Most often & $50(3.8)$ & $224(19.0)$ & $169(13.1)$ & $255(21.8)$ & $698(14.1)$ \\
\hline Not/sometimes & $1264(96.2)$ & $957(81.0)$ & $1119(86.9)$ & $914(78.2)$ & $4254(85.9)$ \\
\hline \multicolumn{6}{|c|}{ Parents reporting financial stress } \\
\hline Yes & $244(18.6)$ & $399(33.8)$ & $243(18.9)$ & $232(19.8)$ & $1118(22.6)$ \\
\hline No & $1053(80.1)$ & $763(64.6)$ & 1019 (79.1) & 919 (78.6) & $3754(75.8)$ \\
\hline
\end{tabular}

${ }^{\mathrm{a}} \mathrm{SDQ}-\mathrm{TDS}=$ Strengths and Difficulties - Total Difficulties Score, SD = Standard Deviation.

1.64-2.62) and fathers (OR 1.46, 95\% CI 0.75-2.84). When analysed stratified by country, increased odds of mental health problems were found among children to time pressured parents in all the Nordic countries; Denmark OR 2.31 (95\% CI 1.18-4.54), Finland OR 2.05 (95\% CI 1.383.05), Norway OR 2.00 (95\% CI 1.26-3.20) and Sweden OR 1.82 (95\% CI 1.21-2.73). When analysed by age groups, the results indicated the strongest association between parents' time pressure and mental health problems among boys 7-12 years old and girls 13-16 years old (Table 3 ) but when tested as the interaction time pressure*age* gender the differences in ORs could not be confirmed statistically significant.

\section{Discussion}

The main finding of the present study was that children of parents who experienced time pressure 'most often' had higher odds of mental health problems than children of parents who did not or sometimes experience time pressure. To our knowledge no previous studies have investigated this association but the findings are consistent with studies of other parent-related stressors, indicating that

Table 2 Mean and standard deviations of total difficulties score, cut-off points and prevalence of mental health problems

\begin{tabular}{|c|c|c|c|c|c|c|c|c|}
\hline & \multirow[t]{3}{*}{ Age group } & \multirow[t]{3}{*}{ Cut-off } & \multicolumn{3}{|c|}{ Time pressure } & \multicolumn{3}{|c|}{ No time pressure } \\
\hline & & & \multirow[t]{2}{*}{$\mathrm{n}$} & TDS & \multirow[t]{2}{*}{$\mathrm{MHP}^{\mathrm{b}} \%$} & \multirow[t]{2}{*}{$n$} & \multirow{2}{*}{$\begin{array}{l}\text { TDS } \\
\text { Mean (SD) }\end{array}$} & \multirow{2}{*}{$\begin{array}{l}\text { MHP } \\
\%\end{array}$} \\
\hline & & & & Mean (SD) $)^{a}$ & & & & \\
\hline All children & & - & 698 & $8.7(4.8)$ & $18.6^{a}$ & 4254 & $7.4(4.1)$ & $10.1^{c}$ \\
\hline \multirow[t]{4}{*}{ Boys } & Total & - & 364 & $9.0(5.0)$ & 17.5 & 2131 & $7.7(4.2)$ & 9.5 \\
\hline & 4-6 years old & 14 & 104 & $9.5(4.2)$ & 16.5 & 514 & $8.0(3.9)$ & 8.8 \\
\hline & 7-12 years old & 14 & 187 & $9.3(5.3)$ & 21.1 & 993 & $7.8(4.3)$ & 10.7 \\
\hline & 13-16 years old & 13 & 73 & $7.5(4.9)$ & 10.7 & 624 & $7.2(4.1)$ & 9.6 \\
\hline \multirow[t]{4}{*}{ Girls } & Total & - & 334 & $8.4(4.6)$ & 17.8 & 2123 & $7.1(3.9)$ & 9.2 \\
\hline & 4-6 years old & 12 & 92 & $8.6(3.9)$ & 22.0 & 488 & $7.2(3.5)$ & 12.0 \\
\hline & 7-12 years old & 13 & 170 & $8.1(4.8)$ & 16.6 & 998 & $7.1(4.1)$ & 9.6 \\
\hline & 13-16 years old & 13 & 72 & $8.6(5.2)$ & 23.6 & 637 & $6.9(4.0)$ & 7.6 \\
\hline
\end{tabular}

${ }^{\mathrm{a}} \mathrm{TDS}=$ Total Difficulties Score, $\mathrm{SD}=$ Standard Deviation.

${ }^{\mathrm{b}} \mathrm{MHP}=$ Mental Health Problems.

'difference between time pressure and no time pressure significant using Chi2 test $p \leq .001$. 
Table 3 Associations between children's mental health problems and parents' subjective time pressure by gender and age groups

\begin{tabular}{|c|c|c|c|c|c|}
\hline \multirow[t]{3}{*}{ Age group } & & \multicolumn{4}{|c|}{ Mental health problems } \\
\hline & & \multirow[t]{2}{*}{$\bar{n}$} & OR $(95 \% \mathrm{Cl})^{\mathrm{a}}$ & \multirow[t]{2}{*}{$\mathrm{n}$} & \multirow{2}{*}{$\begin{array}{l}\text { Adj } \mathrm{OR}^{\mathrm{b}}(95 \% \mathrm{Cl}) \\
\text { reference: no time pressure }\end{array}$} \\
\hline & & & reference: no time pressure & & \\
\hline All children & & 4923 & $2.03^{* * *}(1.63-2.52)$ & 4850 & $1.87^{* * *}(1.50-2.33)^{c}$ \\
\hline \multirow[t]{4}{*}{ Boys } & Total & 2479 & $1.94^{* * *}(1.43-2.63)$ & 2442 & $1.80^{* * *}(1.32-2.46)$ \\
\hline & 4-6 years & 614 & $2.05^{*}(1.12-3.74)$ & 606 & $1.68(0.89-3.16)$ \\
\hline & $7-12$ years & 1174 & $2.23^{* * *}(1.48-3.34)$ & 1157 & $2.25^{* * *}(1.48-3.41)$ \\
\hline & $13-16$ years & 691 & $1.12(0.52-2.45)$ & 679 & $0.99(0.45-2.20)$ \\
\hline \multirow[t]{4}{*}{ Girls } & Total & 2444 & $2.13^{* * *}(1.57-2.89)$ & 2408 & $1.95^{* * *}(1.42-2.66)$ \\
\hline & 4-6 years & 575 & $2.07^{*}(1.17-3.65)$ & 566 & $2.05^{*}(1.15-3.63)$ \\
\hline & $7-12$ years & 1163 & $1.88^{* *}(1.19-2.97)$ & 1148 & $1.55(0.96-2.50)$ \\
\hline & 13-16 years & 706 & $2.75^{* * *}(1.51-5.03)$ & 694 & $2.67^{* *}(1.45-4.93)$ \\
\hline
\end{tabular}

${ }^{\mathrm{a}} \mathrm{OR}=$ Odds Ratio, $\mathrm{Cl}=$ Confidence Interval.

badjusted for financial stress, other covariates tested for as a confounder: Bullying victimisation, long term illness, parents' marital status, educational level, working hours, long term sick leave.

${ }^{c}$ Hosmer and Lemeshow test $p=.904$, Cox \& Snell $\mathrm{R}^{2} .028$, Nagelkerke $\mathrm{R}^{2} .055$.

${ }^{*} p<.05{ }^{* *} p<.01{ }^{* * *} p \leq .001$.

high parental stress $[25,47]$ as well as work-family conflict [26] are associated with mental health problems among children.

Since, previous studies of the association between parents' time pressure and children's mental health problems is lacking, we used Grant's et al. [24] general conceptual model of the role of stressors in the aetiology of child and adolescent psychopathology and Bronfenbrenner's [20,21] ecological model of human development to explain our results and the hypothesised direction of the association observed.

Parents' experience of time pressure is not necessarily completely related to crude lack of time, rather, we propose it to be considered a symptom of tensions in parents' everyday life. Whether these tensions originate from work life, family life, or parents' own or societal expectations, they are examples of processes in children's external ecological systems that according to Bronfenbrenner's ecological model $[20,21]$ affect health and development. As such parents' perceived time pressure, can be considered a potential stressor in children's and adolescents' everyday life, which according to our results is associated with mental health problems. The mechanisms between parents' perceived time pressure and children's mental health problems are most certainly complex. In Figure 2 the theoretical underpinning of the study and the hypothesised direction of the observed association are illustrated in relation to Grant's et al. conceptual model. Moderating and mediating factors potentially important for the mechanisms between parents' time pressure and children's mental health problems are illustrated in a gray scale as they were not possible to analyse in the present study but are considered important to study in future research. The structural aspects (context and conditions) considered important in relation to the observed associations are also illustrated as overarching in relation to the occurring mechanisms, similarly to the macrosystem of Bronfenbrenner's ecological model.

Time pressured parents might not be able to communicate the warmth, consideration and accessibility considered crucial for children's and adolescents' mental health $[48,49]$. Even more so since time pressure can lead to stress/emotional problems among parents $[16,17]$ and typical symptoms of stress are withdrawal and attempts to reduce cognitive and emotional demands. As parental emotional well-being and parenting practices have previously been proposed as potential mechanisms through which low economic status is associated with children's mental health problems [50], it is reasonable to assume that these are also important mediators in the associations between parents' time pressure and child mental health problems.

In Grant's et al. model, child characteristics and environmental context are proposed as moderators that influence the relation between stressors and psychopathology. Previously studies have highlighted individual and social resource factors (e.g. child's personality, good family atmosphere, supportive family network, social support and recreational activities) as important in counteracting mental health problems in case of stress and adversity $[47,51]$. Future research of the association between parents' time pressure and children's mental health problems should include such factors.

The emergence of time pressure as a social problem has been related to economic, cultural and technological changes in society $[9,10]$. These changes are highly 


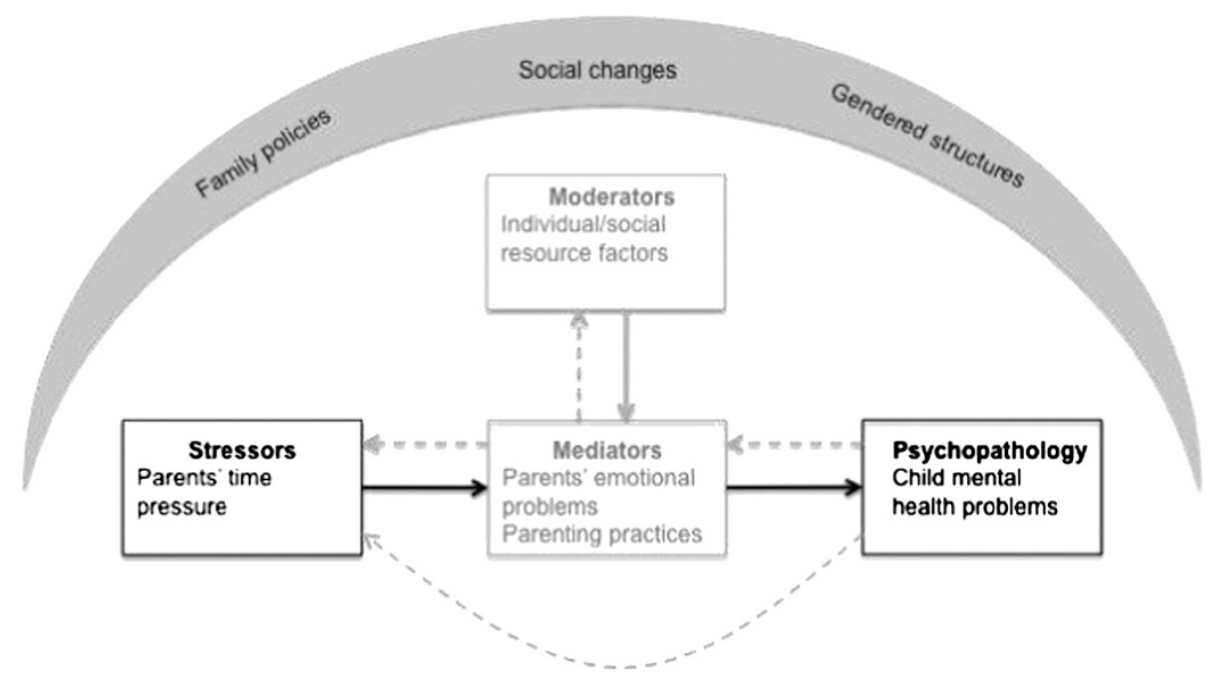

Figure 2 The theoretical underpinnings of the study and the hypothesised directions of the relationships between the variables illustrated in Grant's et al. conceptual model [24]. (Variables and hypothesised directions of associations studied are illustrated in black text and arrows while other variables considered important as well as other potential directions of relationships not studied are illustrated in gray text and arrows).

apparent in the everyday life of families in the Nordic countries where the dual-earner/dual-carer model has become the norm [1,52]. Many Nordic families need two breadwinners to manage regular expenses and the generous day-care system makes it possible even for single parents to combine work and childcare. The context of the present study was the welfare states of the Nordic countries but it can be assumed that parents' experiences of time pressure are even more of a challenge in countries with less supportive family policies.

The high degree of gender equality is a successful product of the Nordic welfare system, at least in theory, but maybe not as successful in practice. Women's/mothers' labour market participation has become a norm while fathers' participation in child care is still struggling to become an accepted norm, as illustrated by fathers' perceptions of breaking the societal norms when choosing to work parttime to take care of their children [53]. Such a discrepancy can be a source of imbalance manifested as time pressure. Another possible source of such imbalance is the labour market's demands of effectiveness, accessibility and flexibility, challenging the work-life parity. Further, expectations and ideals emerging in parallel with social changes of modern societies [8] add to an imbalance in everyday life and the experience of time pressure. In congruency with previous research $[15,26]$, the results of the present study therefore emphasise the importance of considering child mental health in a wide perspective of the structural and social relations shaping the context of children's everyday life.

\section{Gender perspectives}

In our estimations of the prevalence of mental health problems among children exposed to parental time pressure we identified gender differences among adolescents (13-16 years old). While the prevalence was almost the same among those exposed to parental time pressure and those not exposed among adolescent boys, the prevalence of mental health problems among adolescent girls was almost three times higher if their parents experienced time pressure. As mentioned before, previous studies of associations between parental time pressure and children's mental health are lacking, not to mention studies about gender differences in such associations. Theories on gender as a social structure and ongoing activity embedded in social interactions $[54,55]$ might shed light on the observed difference in the prevalence of mental health problems between adolescent boys and girls. According to such theories, the social norm of femininity entails caring and taking responsibility for relationships, implying that the parents might raise more demands and implicit expectations on girls to take responsibility for themselves, assist with the household and/or take care of eventual younger siblings, in order to ease the parents' hectic everyday life. Boys, on the other hand, may not be equally expected to carry out tasks related to care and the household and thus not as burdened by their parents time pressure. On the other hand, there might also be potential differences in how adolescent boys and girls express symptoms of mental health problems. As the constructed norms of masculinity often expect boys to be stoic and strong [55], adolescent boys might not express the negative emotions they experience related to the timepressured parent. In a previous study children aged 10, 13 and 15 years old demonstrated an awareness of social expectations of boys to react to both physical and psychological problems with stoicism and strength [56]. 
Likewise, parents might not be as prone to recognising the symptoms expressed by boys, as it doesn't fit the perceived norm of masculinity. Hence, if interactions are gendered in such a way between the time-pressured parent and the adolescent boy there still might be a possibility that the boys were experiencing problems related to their parents' time pressure even though not observed in the estimated prevalence. Even though gender differences in the associations between parents' time pressure and children's mental health problems could not be confirmed statistically significant, the results of this study support that children's mental health problems needs to be considered in the perspective of prevailing gender structures, both when addressed in research and practice.

\section{Methodological considerations}

The main strength of the present study is the possibility to identify intergenerational health linkages as the data consists of information gathered simultaneously about Nordic parents and children in a broad age span. This has the potential to contribute to an increased understanding of the intertwined lives of parents and children. At the same time it should be highlighted that all data was reported by parents, which means that the assessment of children's symptoms was based on the parents' awareness and reporting of the symptoms. However, the parental version of the SDQ has been widely used and found reliable in screening for child mental health problems [57].

The main limitation of the study is the low response rate. A comparison of the study sample to the general population confirmed an underrepresentation of single parents and parents with low educational levels (Table 4). Moreover, it is likely that the prevalence of parents' experiencing time pressure are underestimated in the study as time pressure can be considered a logical reason for not completing an extensive postal questionnaire. The main focus of the study was to study association rather than prevalence. This may reduce limitations due to the low response rate, as studies of association have been found less sensitive to non-response biases than prevalence estimations [58,59]. Important to bear in mind when interpreting and discussing results is to make a distinction between time pressure and stress. The question used was not measuring stress among parents; it was measuring parents' experience of time pressure, which can be seen as an exposing factor likely to lead to stress. Due to the cross-sectional design of the study, no conclusions about causality can be made, just as the possibility of reciprocal associations between parents' time pressure and children's mental health are important to bear in mind. Family relationships are reciprocal in nature and thus it cannot be excluded that parenting a child with mental health problems may contribute to an experience of time pressure, which also Grant et al. argue is relevant for relations among stressors, moderators, mediators and psychopathology in general.

Finally, the questionnaire was addressed to the parent regarded as the primary caregiver, of whom the large majority were mothers, reflecting the social norm of mothers taking the main responsibility in childcare. Accordingly, the fathers participating in the study should be considered norm breaking and the results of the study only valid for parents who are the child's primary caregiver, and not mothers and/or fathers in general. The Nordic variation in the prevalence of experienced time pressure is an interesting issue, at present without any firm explanation. As we have discussed in another article [18], Danes actually do

Table 4 Characteristics of the answering parents (NordChild2011 2-17years old) compared to general population

\begin{tabular}{|c|c|c|c|c|c|c|c|c|c|c|c|c|c|c|c|c|c|c|c|c|}
\hline \multirow{3}{*}{$\begin{array}{l}\mathrm{M}=\text { Male } \\
\mathrm{F}=\text { Female }\end{array}$} & \multicolumn{4}{|c|}{ Denmark } & \multicolumn{4}{|c|}{ Finland } & \multicolumn{4}{|c|}{ Iceland } & \multicolumn{4}{|c|}{ Norway } & \multicolumn{4}{|c|}{ Sweden } \\
\hline & \multicolumn{2}{|c|}{ Respond \% } & \multicolumn{2}{|c|}{$\begin{array}{l}\text { General } \\
\text { pop\% }\end{array}$} & \multicolumn{2}{|c|}{ Respond \% } & \multicolumn{2}{|c|}{$\begin{array}{l}\text { General } \\
\text { pop\% }\end{array}$} & \multicolumn{2}{|c|}{ Respond \% } & \multicolumn{2}{|c|}{$\begin{array}{l}\text { General } \\
\text { pop\% }\end{array}$} & \multicolumn{2}{|c|}{ Respond \% } & \multicolumn{2}{|c|}{$\begin{array}{l}\text { General } \\
\text { pop\% }\end{array}$} & \multicolumn{2}{|c|}{ Respond \% } & \multicolumn{2}{|c|}{$\begin{array}{l}\text { General } \\
\text { pop\% }\end{array}$} \\
\hline & $\bar{M}$ & $F$ & $M$ & $F$ & $\mathrm{M}$ & $F$ & $\bar{M}$ & $F$ & $\bar{M}$ & $F$ & $M$ & $F$ & $\mathrm{M}$ & $F$ & $M$ & $F$ & $\bar{M}$ & $F$ & $M$ & $F$ \\
\hline \multicolumn{21}{|l|}{ Marital status $^{a}$} \\
\hline Married/cohab & \multicolumn{2}{|c|}{87.5} & \multicolumn{2}{|c|}{77.6} & \multicolumn{2}{|c|}{88.5} & \multicolumn{2}{|c|}{79.7} & \multicolumn{2}{|c|}{87.9} & \multicolumn{2}{|c|}{72.2} & \multicolumn{2}{|c|}{87.3} & \multicolumn{2}{|c|}{81.0} & \multicolumn{2}{|c|}{88.1} & \multicolumn{2}{|c|}{76.6} \\
\hline Single & 1.6 & 10.9 & 3.9 & 18.5 & 1.4 & 10.1 & 2.7 & 17.6 & 0.7 & 11.3 & 2.5 & 25.3 & 2.2 & 10.5 & 3.2 & 15.8 & 1.6 & 10.3 & 4.8 & 18.6 \\
\hline \multicolumn{21}{|c|}{ Educational level $^{b}$} \\
\hline Lower levels & 45.8 & 56.0 & 71.8 & 64.4 & 59.2 & 60.1 & 79.1 & 74.6 & 47.7 & 43.6 & 73.3 & 63.8 & 43.6 & 38.2 & 69.9 & 65.5 & 53.9 & 46.1 & 66.5 & 58.9 \\
\hline University level & 54.2 & 44.0 & 28.2 & 35.6 & 40.8 & 39.9 & 20.9 & 25.3 & 52.3 & 56.4 & 26.7 & 36.2 & 56.4 & 61.8 & 30.1 & 34.5 & 52.1 & 53.9 & 33.5 & 41.1 \\
\hline \multicolumn{21}{|c|}{ Country of birth ${ }^{c}$} \\
\hline Nordic & 89.0 & 94.4 & 90.3 & 90.6 & 97.4 & 98.8 & 95.0 & 95.3 & 92.2 & 96.9 & 91.2 & 91.0 & 88.6 & 90.5 & 89.8 & 90.4 & 86.4 & 89.5 & 87.7 & 87.7 \\
\hline Non-Nordic & 11.0 & 5.6 & 9.7 & 9.4 & 2.6 & 1.2 & 4.3 & 4.1 & 7.8 & 3.1 & 8.8 & 9.0 & 11.4 & 9.5 & 10.2 & 9.6 & 13.6 & 10.5 & 12.3 & 12.3 \\
\hline
\end{tabular}

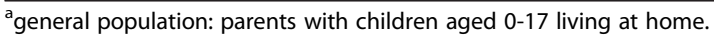

${ }^{\mathrm{b}}$ general population: DK people aged 25-69, FI people aged 25-69, IS people aged 25-74, NO people >25, SE people aged 25-74.

'general population: the whole population.

Source: National statistical institutes. 
experience stress in everyday life according to previous studies $[60,61]$, just as psychologists describe high pace and multiple roles as main challenges in everyday life of Danish parents [62]. Similarly to our results, however, a lower proportion of Danish workers reported workrelated stress as compared to the Nordic and European average [63]. Hence, further research on the prevalence, origin and impacts of parents' time pressure is needed.

\section{Conclusions}

This study found that parents' subjective time pressure was associated with increased mental health problems among children and adolescents. Given that time pressure is a growing feature of modern societies, such as those in the Nordic countries, the results might contribute to an explanation as to why mental health problems are common among children in the Nordic countries in spite of otherwise favourable conditions for child health and development. Additional research on the linkage between parents' experienced time pressure and children's and adolescents' mental health problems is needed to confirm the novel findings of this study. Further research is also needed regarding the mechanisms between parents' time pressure and children's mental health problems as well as concerning the gendered patterns of mental health problems among children and adolescents.

\section{Competing interests}

The authors declare that they have no competing interests.

\section{Authors' contributions}

HG drafted and wrote the main part of the manuscript and conducted the statistical analysis. YB contributed with ideas and assistance in the statistical analysis as well as to the drafting and revision of the manuscript. MP contributed to the conception and design of the study, the acquisition, analysis and interpretation of the data. GH and LP were involved in drafting the manuscript, revising it critically and contributed with important theoretical content. All authors have read and approved the final manuscript.

\section{Acknowledgements}

The NordChild studies are conducted in collaboration between the Nordic countries and we want to express our gratitude to the members of the NordChild research group.

\section{Author details \\ ${ }^{1}$ Department of Public Health and Community Medicine, Section of Social Medicine, Sahlgrenska Academy at University of Gothenburg, Gothenburg Sweden. ${ }^{2}$ Department of Nursing, Health and Culture, University West, 461 86 Trollhättan, Sweden. ${ }^{3}$ Department of Social Work, University of Gothenburg, Gothenburg, Sweden. ${ }^{4}$ Centre for applied biostatistics, Department of Public Health and Community Medicine, Section of Occupational and Environmental Medicine, Sahlgrenska Academy at University of Gothenburg, Gothenburg, Sweden. ${ }^{5}$ Unit for Health Promotion Research, University of Southern Denmark, Esbjerg, Denmark.}

Received: 22 July 2014 Accepted: 13 March 2015

Published online: 10 April 2015

\section{References}

1. Eydal GB, Rostgaard T. Gender equality revisited? Changes in Nordic childcare policies in the 2000s. Soc Policy Adm. 2011;45:161-79.

2. Ellingsæter AL, Leira A. Politicising Parenthood in Scandinavia: Gender Relations in Welfare States. Bristol: The Policy Press; 2006.
3. Byron K. A meta-analytic review of work-family conflict and its antecedents. J Vocat Behav. 2005;67:169-98.

4. Statistics Sweden (SCB). Swedish Time Use Survey 2010/2011. Living conditions Report 123. Stockholm: Statistics Sweden; 2012.

5. Official Statistics of Finland (OSF). Time use survey [e-publication]. Time use changes through the 2000s. Helsinki: Statistics Finland; 2011 [http://www. stat.fi/til/akay/2009/05/akay_2009_05_2011-12-15_tie_001_en.html]

6. Bonke J. Har vi Tid Til Velfærd? Om Danskernes Brug Af Deres Tid Ude Og Hjemme. [Do We Have Time for Welfare? About Danes' Time Use in and Outside the Home]. Copenhagen: Rockwool Fondens Forskningsenhed; 2012.

7. Statistics Norway (SSB). Foreldrenes tidsbruk: Fedre deltar mer i husarbejd og omsorg. [Parents' time use: Fathers' increased participation in housework and care]. Oslo: Statistics Norway; 2012 [http://www.ssb.no/kultur-og-fritid/ artikler-og-publikasjoner/fedre-deltar-mer-i-husarbeid-og-omsorg].

8. Garhammer M. Pace of life and enjoyment of life. J Happiness Stud. 2002;3:217-56.

9. Rosa H. Social acceleration: ethical and political consequences of a desynchronized high-speed society. Constellations. 2003;10:3-33.

10. Southerton $D$, Tomlinson M. Pressed for time'-the differential impacts of a 'time squeeze. Sociol Rev. 2005;53:215-39.

11. Szollos A. Toward a psychology of chronic time pressure: conceptual and methodological review. Time Soc. 2009;18:332-50.

12. Roxburgh $\mathrm{S}$. Racing through life: the distribution of time pressures by roles and role resources among full-time workers. J Fam Econ Iss. 2002;23:121-45.

13. Larsson J. Om Föräldrars Tidspress: Orsaker Och Förändringsmöjligheter [Parents' Time Pressure: Causes and Opportunities for Change]. Volume 139. Gothenburg: Department of Sociology, Gothenburg University; 2007 [vol. 139].

14. Stenhammar C, Wells M, Ahman A, Wettergren B, Edlund B, Sarkadi A. "Children are exposed to temptation all the time"- parents' lifestyle-related discussions in focus groups. Acta Paediatr. 2012;101:208-15.

15. Gunnarsdottir H, Povlsen L, Ringsberg KC. Health lifestyles of pre-school children in Nordic countries: parents' perspectives. Health Promot Int. 2013; Nov 12 [E-pub ahead of print] PMID: 24221529.

16. Roxburgh S. Parental time pressures and depression among married dual-earner parents. J Fam Issues. 2012;33:1027-53.

17. Johnson SE. Time pressure and the wellbeing of parents with young children in Australia, Volume PhD thesis. Curtin: Curtin University of Technology, School of Public Health; 2010

18. Gunnarsdottir H, Petzold M, Povlsen L. Time pressure among parents in the Nordic countries: a population-based cross-sectional study. Scand J Public Health. 2014:42:137-45.

19. Turney K, Lee H, Mehta N. Introduction. The social determinants of health. Soc Sci Med. 2013;95:1-5

20. Bronfenbrenner U. The Ecology of Human Development: Experiments by Nature and Design. Cambridge: Harvard University Press; 1979.

21. Bronfenbrenner U. Ecology of the family as a context for human development: research perspectives. Dev Psychol. 1986;22:723-42.

22. Kieling C, Baker-Henningham H, Belfer M, Conti G, Ertem I, Omigbodun O, et al. Child and adolescent mental health worldwide: evidence for action. Lancet. 2011;378:1515-25.

23. Heiervang E, Stormark KM, Lundervold AJ, Heimann M, Goodman R, Posserud M-B, et al. Psychiatric disorders in Norwegian 8-to 10-year-olds: an epidemiological survey of prevalence, risk factors, and service use. J Am Acad Child Adolesc Psychiatry. 2007;46:438-47.

24. Grant KE, Compas BE, Stuhlmacher AF, Thurm AE, McMahon SD, Halpert JA. Stressors and child and adolescent psychopathology: moving from markers to mechanisms of risk. Psychol Bull. 2003;129:447.

25. Van Oort FVA, Verhulst FC, Ormel J, Huizink AC. Prospective community study of family stress and anxiety in (pre) adolescents: the TRAILS study. Eur Child Adolesc Psychiatry. 2010;19:483-91

26. Strazdins L, OBrien LV, Lucas N, Rodgers B. Combining work and family: rewards or risks for children's mental health? Soc Sci Med. 2013;87:99-107.

27. Hankin BL, Mermelstein R, Roesch L. Sex differences in adolescent depression: stress exposure and reactivity models. Child Dev. 2007;78:279-95.

28. Rudolph KD. Gender differences in emotional responses to interpersonal stress during adolescence. J Adolesc Heal. 2002;30(4, Suppl 1):3-13.

29. Baviskar S. Does child gender moderate the relationship between interparental conflict and child outcomes? Findings from the Danish longitudinal study of children. Nor Epidemiol. 2010;20:63-75.

30. Byrne D, Davenport S, Mazanov J. Profiles of adolescent stress: the development of the adolescent stress questionnaire (ASQ). J Adolesc. 2007;30:393-416. 
31. Byrne D, Thomas K, Burchell J, Olive L, Mirabito N. Stressor experiences in primary school-aged children: development of a scale to assess profiles of exposure and effects on psychological well-being. Int J Stress Manag. 2011;18:88-111.

32. American Academy of Pediatrics. Supplemental Appendix S9: glossary of mental health and substance abuse terms. Pediatrics. 2010;125(Supplement):S161-70.

33. Foy JM, Kelleher KJ, Laraque D. Enhancing pediatric mental health care: strategies for preparing a primary care practice. Pediatrics. 2010;125(Supplement 3):S87-108.

34. Goodman R. Psychometric properties of the strengths and difficulties questionnaire. J Am Acad Child Adolesc Psychiatry. 2001:40:1337-45.

35. Niclasen J, Teasdale TW, Andersen A-MN, Skovgaard AM, Elberling H, Obel C. Psychometric properties of the Danish Strength and Difficulties Questionnaire: the SDQ assessed for more than 70,000 raters in four different cohorts. PLoS One. 2012; : $: 32025$.

36. Malmberg M, Rydell A, Smedje H. Validity of the Swedish version of the Strengths and Difficulties Questionnaire (SDQ-Swe). Nord J Psychiatry. 2003:57:357-63.

37. Koskelainen M, Sourander A, Kaljonen A. The Strengths and Difficulties Questionnaire among Finnish school-aged children and adolescents. Eur Child Adolesc Psychiatry. 2000;9:277-84.

38. Goodman R. The Strengths and Difficulties Questionnaire: a research note. J Child Psychol Psychiatry. 1997;38:581-6.

39. Goodman A, Lamping DL, Ploubidis GB. When to use broader internalising and externalising subscales instead of the hypothesised five subscales on the Strengths and Difficulties Questionnaire (SDQ): data from British parents, teachers and children. J Abnorm Child Psychol. 2010;38:1179-91.

40. Obel C, Heiervang E, Rodriguez A, Heyerdahl S, Smedje H, Sourander A, et al. The strengths and difficulties questionnaire in the Nordic countries. Eur Child Adolesc Psychiatry. 2004;13 Suppl 2:11/32-9.

41. Goodman R, Ford T, Simmons H, Gatward R, Meltzer H. Using the Strengths and Difficulties Questionnaire (SDQ) to screen for child psychiatric disorders in a community sample. Br J Psychiatry. 2000;177:534-9.

42. Smedje H, Broman J-E, Hetta J, Von Knorring A-L. Psychometric properties of a Swedish version of the "Strengths and Difficulties Questionnaire". Eur Child Adolesc Psychiatry. 1999;8:63-70.

43. Statistics Sweden (SCB). Tid För Vardagsliv. Kvinnors Och Mäns Tidsanvändning 1990/91 Och 2000/01. Report no 99. [Time for Everyday Life. Women's and Men's Time Use 1990/91 and 2000/01]. Stockholm: Statistics Sweden; 2003.

44. Arseneault $L$, Bowes $L$, Shakoor $S$. Bullying victimization in youths and mental health problems: "Much ado about nothing". Psychol Med. 2010;40:717-29.

45. Zwierzynska K, Wolke D, Lereya TS. Peer victimization in childhood and internalizing problems in adolescence: a prospective longitudinal study. J Abnorm Child Psychol. 2013;41:309-23.

46. Reiss F. Socioeconomic inequalities and mental health problems in children and adolescents: a systematic review. Soc Sci Med. 2013;90:24-31.

47. Wille N, Bettge S, Ravens-Sieberer U. Risk and protective factors for children's and adolescents' mental health: results of the BELLA study. Eur Child Adolesc Psychiatry. 2008;17 Suppl 1:133-47.

48. Waylen A, Stallard N, Stewart-Brown S. Parenting and health in mid-childhood: a longitudinal study. Eur J Public Health. 2008;18:300-5.

49. Morgan Z, Brugha T, Fryers T, Stewart-Brown S. The effects of parent-child relationships on later life mental health status in two national birth cohorts. Soc Psychiatry Psychiatr Epidemiol. 2012;47:1707-15.

50. Bøe T, Sivertsen B, Heiervang E, Goodman R, Lundervold AJ, Hysing M. Socioeconomic Status and Child Mental Health: the role of parental emotional well-being and parenting practices. J Abnorm Child Psychol. 2014;42:705-15.

51. Foy JM, Perrin J. Enhancing pediatric mental health care: strategies for preparing a community. Pediatrics. 2010;125 Suppl:S75-86.

52. Datta Gupta N, Smith N, Verner M. The impact of Nordic countries' family friendly policies on employment, wages, and children. Rev Econ Househ. 2008;6:65-89.

53. Larsson J. Studier i tidsmässig välfärd-med fokus på tidsstrategier och tidspolitik för småbarnsfamiljer [Studies in temporal welfare - focusing on time strategies and time politics for families with small children], Volume Studies in. Gothenburg: University of Gothenburg, Department of Sociology; 2012.

54. West C, Zimmerman DH. Doing gender. Gend Soc. 1987;1:125-51.

55. Connell R. Gender. 2nd ed. Cambridge: Polity Press; 2009.

56. Maclean A, Sweeting H, Hunt K. "Rules" for boys, "guidelines" for girls: gender differences in symptom reporting during childhood and adolescence. Soc Sci Med. 2010;70:597-604.
57. Stone $L L$, Otten R, Engels RCME, Vermulst AA, Janssens JMAM. Psychometric properties of the parent and teacher versions of the strengths and difficulties questionnaire for 4-to 12-year-olds: a review. Clin Child Fam Psychol Rev. 2010;13:254-74.

58. Van Loon AJM, Tijhuis M, Picavet HSJ, Surtees PG, Ormel J. Survey nonresponse in the Netherlands: effects on prevalence estimates and associations. Ann Epidemiol. 2003;13:105-10.

59. Martikainen $\mathrm{P}$, Laaksonen M, Piha K, Lallukka T. Does survey non-response bias the association between occupational social class and health? Scand J Public Health. 2007:35:212-5.

60. Nielsen L, Curtis T, Kristensen TS, Rod Nielsen N. What characterizes persons with high levels of perceived stress in Denmark? A national representative study. Scand J Public Health. 2008;36:369-79.

61. Deding M, Lausten M. Gendered time-crunch and work factors in Denmark. Soc Indic Res. 2011;101:249-53.

62. Dencik L. Familie Og Børn I En Opbrudstid [Families and Children in Breaking Times]. Hans Reitzels Forlag: Copenhagen; 2008.

63. EU-OSHA. European Opinion Poll on Occupational Safety and Health. Bilbao, Spain: European Agency for Safety and Health at Work; 2013.

\section{Submit your next manuscript to BioMed Central and take full advantage of:}

- Convenient online submission

- Thorough peer review

- No space constraints or color figure charges

- Immediate publication on acceptance

- Inclusion in PubMed, CAS, Scopus and Google Scholar

- Research which is freely available for redistribution 